\title{
Reference Values of Sensory and Motor Nerve Conduction for Patients of a Fourth Level Hospital in Bogotá, Colombia
}

\section{Valores de referencia de neuroconducción sensitiva y motora para pacientes de un hospital de cuarto nivel en Bogotá (Colombia)}

Received: 15/01/2020 | Accepted: 01/05/2020

\section{Carolina García-Alfonso}

Schoof of Medicine, Pontificia Universidad Javeriana.

Neurology Unit, Hospital Universitario San Ignacio,

Bogotá, Colombia

Nancy Molina

Neurology Unit, Hospital Universitario San Ignacio,

Bogotá, Colombia

Sonia Millán

Neurology Unit, Hospital Universitario San Ignacio,

Bogotá, Colombia

a Corresponding author: caro.med.garcia@gmail.com

How to cite: García-Alfonso C, Molina N, Millán S. Reference values of sensory and motor nerve conduction for patients of a fourth level hospital in Bogotá, Colombia. Univ. Med. 2020;61(4). https://do i.org/10.11144/Javeriana.umed61-4.moto

\begin{abstract}
Objective: To establish reference values of motor and sensory nerve conductions and late responses for the Electrodiagnostic Laboratory of Hospital Universitario San Ignacio. Materials and Methods: Sensory and motor nerve conduction studies were performed on 77 healthy volunteers between 18 and 65 years old, for a total of 154 analyzes, using a standardized technique for measurement. Results: Motor nerve conductions were performed measuring latency, amplitude and conduction velocity for the median, ulnar, tibial, and peroneal nerve. Sensory nerve conductions were performed measuring latency and conduction velocity for the median, ulnar, and sural nerve. A ShapiroWilk test was performed, finding that the amplitude parameters for sensory nerve conductions did not follow a normal distribution, so percentile analysis was performed. Only sex showed a statistically significant difference for the parameters of tibial nerve amplitude $(p=0.0099)$ being greater in women, and latency of the peroneal nerve $(p=0.0091)$ being greater in men. Conclusion: Normal parameters were established for motor and sensory nerve conductions and late responses for the Electrodiagnostic Laboratory of Hospital Universitario San Ignacio, which mostly correlate with the current reference data, with certain differences that could be related with height and sex. However, additional studies are required to establish this difference.
\end{abstract}

Keywords nerve conduction studies; $\mathrm{f}$ response; $\mathrm{h}$ reflex.

\section{RESUMEN}

Objetivo: Establecer valores de referencia de las neuroconducciones motoras y sensitivas y de las respuestas tardías para el Laboratorio de Electrodiagnóstico del Hospital Universitario San Ignacio. Materiales y métodos: Se realizaron estudios de neuroconducción sensitiva y motora 
de las 4 extremidades, a 77 voluntarios sanos entre los 18 y los 65 años de edad, para un total de 154 registros, usando una técnica estandarizada para la medición. Resultados: Se realizaron neuroconducciones motoras que midieron latencia, amplitud y velocidad de los nervios mediano, cubital, tibial y peronero. También se realizaron neuroconducciones sensitivas que midieron latencia y velocidad de los nervios mediano, cubital y sural. Un test de Shapiro-Wilk encontró que los parámetros de amplitud para las neuroconducciones sensitivas no seguían una distribución normal, por lo cual se hizo análisis de percentiles. Solo el sexo mostró una diferencia estadísticamente significativa para los parámetros de amplitud del nervio tibial $(\mathrm{p}=0,0099)$, siendo mayor en mujeres, y latencia del nervio peroneo $(p=0,0091)$, siendo mayor en hombres. Conclusiones: Se establecieron los parámetros de referencia para las neuroconducciones motoras, sensitivas y las respuestas tardías para el Laboratorio de Electrodiagnóstico del Hospital Universitario San Ignacio, los cuales se correlacionan en su mayoría con los datos de referencia actuales, con ciertas diferencias que podrían estar relacionadas con la estatura y el sexo. Sin embargo, se requieren estudios adicionales para establecer esta diferencia.

Palabras clave

neuroconducciones; reflejo h; onda f.

\section{Introduction}

Electrodiagnostic studies are an important tool in diseases that affect both the peripheral and central nervous system. Neuroconduction studies are non-invasive medical procedures that help evaluate neuromuscular diseases because they provide a physiological assessment of the peripheral nerve, muscle, neuromuscular junction, dorsal root ganglion neuron and anterior horn neuron. Motor nerve conduction studies assess the motor axons by selectively recording the muscle response to nerve stimulation. Sensory nerve conduction studies evaluate sensory axons by recording directly from the peripheral nerves (1).

Most of the normality parameters for nerve conduction and late response studies used for the population of Hospital Universitario San Ignacio and, in general, for Latin American countries were extrapolated from Buschbacher studies of 1999 (1-7). However, there were important differences in the characteristics of the population selected for these studies.
There is limited information regarding normality parameters in Latin America. For the Colombian population, a research protocol from Hospital Militar Central de Bogotá of 2013 (8) was found, without a plan for recording late responses, and a study from the Universidad Nacional de Colombia of 2014 (9), which describes the reference values of lower limb nerve conduction studies in young adults. Several studies conducted in Latin America were found defining normality parameters of specific information, such as evoked potentials (10) or nerve conduction studies in healthy adults (11), and no reference data were found to estimate late responses.

The values of each record vary according to each laboratory, depending on factors such as height above sea level, room temperature or patient's height. From this we see the importance of having normality parameters for nerve conduction and late response studies for each electrophysiology and electrodiagnostic laboratory.

The aim of this study is to find the normality values for motor nerve conductions of the median, ulnar, tibial and peroneal nerves, sensory nerve conductions of the median, ulnar and sural nerves, and normality values for the F-wave and $\mathrm{H}$-reflex latencies for the Electrodiagnostic Laboratory of Hospital Universitario San Ignacio.

\section{Materials and methods}

Descriptive cross-sectional study conducted at the Neurophysiology and Electrodiagnostic Laboratory of Hospital Universitario San Ignacio, Bogotá. By non-probabilistic sampling and according to the estimates of the parameters found, the minimum sample size required was 153 records, considering a final precision of $10 \%$ in the estimation of the mean and its measures of dispersion and central tendency to generate reference values for motor and sensory nerve conduction. A total of 77 healthy adult patients were included, for whom 154 records were collected. The age of inclusion was 18 to 65 years of age. 
Healthy companions of hospital patients were informed about the study, and also hospital workers and undergraduate and graduate students. A questionnaire with inclusion and exclusion criteria was administered to those who decided to enter the study voluntarily (see the supplementary material), and those who met the eligibility criteria were provided with the informed consent form for completion.

The variables investigated were latency, amplitude and velocity of the median, ulnar, tibial and peroneal motor nerves, and of the median, ulnar and sural sensory nerves. Latencies of the $\mathrm{F}$-wave and $\mathrm{H}$-reflex were also measured. The variables were analyzed with the Stata 14 software. After obtaining the measures of central tendency of the variables, a Shapiro-Wilk test was carried out to establish if the variables have a normal distribution, for subsequent analysis.

\section{Measurement technique}

Nerve conduction studies were performed with Nicolet VikingQuest electrodiagnostic system, Nicolet S403 electrical stimulators, gold cup and ring surface recording electrodes, at an average room temperature of $18-20^{\circ} \mathrm{C}$.

Filters were set at $1 \mathrm{~Hz}-10 \mathrm{KHz}$, gain of $5 \mathrm{mV}$ per division, electrical pulse duration in $200 \mathrm{~ms}$, and current between 20 and $50 \mathrm{~mA}$ for motor nerve conductions, and $20 \mathrm{~Hz}-3 \mathrm{KHz}$, gain of $20 \mu \mathrm{V}$, electrical pulse duration between 100 and $200 \mathrm{~ms}$, and current between 15 and $30 \mathrm{~mA}$ for sensory nerve conductions. The earth pole earth electrode is located on the dorsum of the hand and the dorsum of the foot, respectively.

The active recording electrode (also called G1) is placed in the center of the muscle belly, over the motor plate, and the reference electrode (also called G2) is placed distal to the active electrode, on the tendon of the muscle. The stimulator is placed over the nerve that innervates the muscle, with the cathode located on the side of the active electrode. For the motor nerve conductions, a stimulus was performed at a distance of $8 \mathrm{~cm}$ from the $\mathrm{G} 1$ electrode, and for the sensory nerve conductions at a distance of 14 $\mathrm{cm}$.

\section{Upper limbs}

For the motor nerve conduction of the median nerve, the G1 electrode was placed on the belly of the abductor pollicis brevis and the G2 electrode was placed $4 \mathrm{~cm}$ distally over the first metacarpophalangeal joint. The distal stimulation site was located $8 \mathrm{~cm}$ proximal to the $\mathrm{G} 1$ electrode, between the flexor carpi radialis tendon and the palmaris longus tendon, and the proximal was located medial to distal third of the biceps tendon.

For the sensory nerve conduction of the median nerve, the G1 ring electrode was placed on the second finger, and $\mathrm{G} 2$ electrode was placed $4 \mathrm{~cm}$ distal to the $\mathrm{G} 1$ electrode. The stimulus was performed $14 \mathrm{~cm}$ proximal to the G1 electrode, and posterior to the flexor carpi ulnaris tendon.

For the motor nerve conduction of the ulnar nerve, the G1 electrode was placed on the belly of the abductor digiti minimi, and the G2 electrode was placed $4 \mathrm{~cm}$ distally over the fifth metacarpophalangeal joint. The distal stimulation site was located $8 \mathrm{~cm}$ proximal to the G1 electrode, posterior to the flexor carpi ulnaris tendon, and the proximal one was located $3-4 \mathrm{~cm}$ distal to the medial epicondyle with the elbow at 90 degrees of flexion.

For sensory nerve conduction of the ulnar nerve, the G1 ring electrode was placed on the fifth finger; the $\mathrm{G} 2$ electrode was placed $4 \mathrm{~cm}$ distal to the G1 electrode. The ulnar nerve stimulus was performed $14 \mathrm{~cm}$ proximal to the G1 electrode, and posterior to the flexor carpi ulnaris tendon.

\section{Lower limbs}

For the motor nerve conduction of the tibial nerve, the G1 electrode was placed over the abductor hallucis, medial to the foot, anterior and inferior to the navicular tuberosity, and the G2 electrode was placed distal to the first metatarsophalangeal joint, on its medial surface. 
The distal stimulation site is $8 \mathrm{~cm}$ proximal to the G1 electrode, behind the tibial malleolus, and the proximal one is in the popliteal fossa, medial or lateral to the midline.

For the motor nerve conduction of the peroneal nerve, the G1 electrode is located over the midpoint of the extensor digitorum brevis muscle, on the dorsum of the foot, and the G2 electrode is located distal to the fifth metatarsophalangeal joint. The distal stimulation site is $8 \mathrm{~cm}$ proximal to the $\mathrm{G} 1$ electrode, lateral to the anterior tibial tendon, and the proximal one was located posterior and inferior to the fibular head.

For the sensory nerve conduction of the sural nerve, the G1 electrode was located behind the lateral malleolus, and the G2 electrode was located distal to it. The stimulation site was located $14 \mathrm{~cm}$ proximal to the G1 electrode, lateral to the midline at the back and lower portion of the leg.

\section{Late responses}

The F-wave is a late motor response that occurs after the compound muscle action potential. In the lower limbs, when the peroneal or tibial nerves are stimulated, the $\mathrm{G} 1$ and $\mathrm{G} 2$ electrodes are placed in the same way as in the motor nerve conductions. The F-wave normally occurs at a latency of 45 to $56 \mathrm{~ms}$. The gain was set to 200 or $500 \mu \mathrm{V}$, and the sweep time to 5 or $10 \mathrm{~ms}$, depending on the length of the nerve. Supramaxial stimulation was performed, and the direction of the stimulator was reversed so that the cathode was proximal. The stimulus speed was $0.5 \mathrm{~Hz}$, in order to avoid the effects of the previous stimulus on a later response. Ten records were obtained for each F-wave.

The H-reflex is a true reflex, with sensory afference, synapses and motor efference. It is obtained only by stimulating the tibial nerve in the popliteal fossa and registering in the soleus muscle. The gain was set from 200 to $500 \mu \mathrm{V}$. Typical latency is approximately $30 \mathrm{~ms}$. The sweep time was $10 \mathrm{~ms}$, with a stimulus duration of $1 \mathrm{~ms}$.
The G1 electrode was placed over the proximal part of the soleus muscle (where it meets the two gastrocnemius muscle bellies); the $\mathrm{G} 2$ reference electrode was placed over the Achilles tendon. The stimulus was performed in the popliteal fossa with the cathode located towards the proximal area, and starting with a low stimulus intensity. It should be stimulated at a rate not faster than once every $2 \mathrm{~s}(0.5 \mathrm{~Hz})$, in order to avoid the effects of the previous stimulus on a later response. The H-reflex is thriphasic; it appears with latencies of 25 to $34 \mathrm{~ms}$, and is recorded with the muscle at rest.

\section{Results}

77 patients, 31 men and 46 women, aged between 18 and 65 years were included in the study. This represents an analysis of 154 nerves for motor and sensory nerve conduction of the 4 extremities, and 142 analyses of late responses ( $\mathrm{F}$-wave and $\mathrm{H}$-reflex). The mean age was 32.3 years, and the mean total height was $167 \mathrm{~cm}(173 \mathrm{~cm}$ in men and $163 \mathrm{~cm}$ in women).

The mean, standard deviation, and 15th and 75 th percentiles for each parameter of motor and sensory nerve conductions and late responses, are shown in tables 1,2 , and 3 , respectively.

\section{Table 1}

Motor nerve conductions

\begin{tabular}{|c|c|c|c|c|c|}
\hline & $\mathrm{n}=154$ & & & $\mathrm{n}=62$ & $\mathrm{n}=92$ \\
\hline Median & Total $^{*}$ & 15 th perc ${ }^{* *}$ & 75th perce* & Men & Women \\
\hline Latency & $3.2 \pm 1$ & 2.8 & 3.4 & $3.2 \pm 0.9$ & $3.2 \pm 1$ \\
\hline Amplitude & $9.7 \pm 6.6$ & 6.5 & 11.8 & $9.4 \pm 6.4$ & $9.8 \pm 6.8$ \\
\hline Velocity & $59 \pm 8.2$ & 54 & 62 & $59 \pm 8.6$ & $58.7 \pm 8$ \\
\hline Ulnar & Total & 15th perc & 75th perc & Men & Women \\
\hline Latency & $3 \pm 0.6$ & 2.7 & 3.2 & $3 \pm 0.6$ & $2.9 \pm 0.6$ \\
\hline Amplitude & $9.2 \pm 4.6$ & 6.8 & 10.9 & $9.2 \pm 4.4$ & $9.2 \pm 4.6$ \\
\hline Velocity & $63.6 \pm 14.6$ & 56 & 68 & $62 \pm 10.8$ & $64 \pm 16.4$ \\
\hline Tibial & Total & 15 th perc & 75 th perc & Men & Women \\
\hline Latency & $3.4 \pm 1$ & 3 & 3.6 & $3.5 \pm 1.2$ & $3.3 \pm 0.8$ \\
\hline Amplitude & $14 \pm 9$ & 9.2 & 17 & $13 \pm 7.2$ & $15 \pm 10$ \\
\hline Velocity & $49 \pm 7.6$ & 45 & 51 & $49 \pm 8.4$ & $48.8 \pm 7$ \\
\hline Peroneal & Total & 15 th perc & 75th perc & Men & Women \\
\hline Latency & $3.4 \pm 1.4$ & 2.8 & 3.7 & $3.6 \pm 1.4$ & $3.3 \pm 1.4$ \\
\hline Amplitude & $7.36 \pm 5.8$ & 4.2 & 9.4 & $7.5 \pm 6$ & $7.3 \pm 5.6$ \\
\hline Velocity & $51 \pm 9$ & 47 & 54 & $51.6 \pm 9.2$ & $51 \pm 8.6$ \\
\hline
\end{tabular}

**15th and 75 th percentiles for the total sample. 
Table 2

Sensory nerve conductions

\begin{tabular}{|c|c|c|c|c|c|}
\hline \multicolumn{6}{|c|}{ Sensory nerve conduction } \\
\hline & $\mathrm{n}=154$ & & & $\mathrm{n}=62$ & $\mathrm{n}=92$ \\
\hline Median & Total ${ }^{*}$ & 15th perc ${ }^{* *}$ & 75th perce** & Men & Women \\
\hline Latency & $2.3 \pm 0.52$ & 2 & 2.4 & $2.3 \pm 0.48$ & $2.3 \pm 0.54$ \\
\hline Amplitude & $48^{\dagger}$ & 24 & 64 & $45^{\top}$ & $50^{\top}$ \\
\hline Velocity & $58 \pm 13$ & 52 & 62 & $58 \pm 13$ & $58 \pm 13$ \\
\hline Ulnar & Total ${ }^{*}$ & 15th perc ** & 75th perc $* *$ & Men & Women \\
\hline Latency & $2.2 \pm 0.5$ & 2 & 2.4 & $2.3 \pm 0.46$ & $2.2 \pm 0.54$ \\
\hline Amplitude & $35^{\dagger}$ & 16 & 47 & $29^{\dagger}$ & $39.4^{\dagger}$ \\
\hline Velocity & $58 \pm 12.4$ & 52 & 63 & $57 \pm 11.7$ & $59 \pm 12.8$ \\
\hline Sural & Total $^{*}$ & 15th perc $* *$ & 75th perc $* *$ & Men & Women \\
\hline Latency & $1.7 \pm 0.52$ & 1.5 & 1.9 & $1.8 \pm 0.54$ & $1.7 \pm 0.52$ \\
\hline Amplitude & $19.7^{\dagger}$ & 7 & 28 & $18^{\top}$ & $21^{\top}$ \\
\hline Velocity & $58.6 \pm 17.4$ & 50 & 63 & $58 \pm 18$ & $59 \pm 17$ \\
\hline
\end{tabular}

*Mean \pm 2 SD.

**15th and 75 th percentiles for the total sample.

$\dagger$ The mean is shown, without SD, since

variables do not follow normal distribution.

\section{Table 3}

Late responses

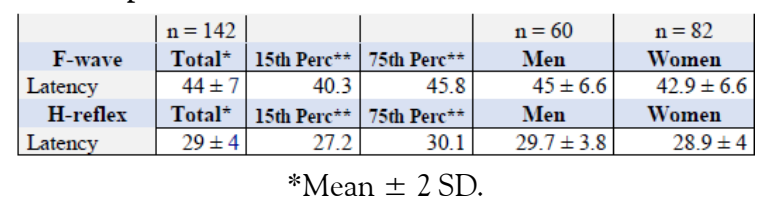

**15th and 75 th percentiles for the total sample.

Variables were analyzed by groups between men and women and a statistically significant difference was found in the amplitude parameters of the tibial nerve $(\mathrm{H}: 13 \pm 7.2 ; \mathrm{M}: 15 \pm 10 ; \mathrm{p}=$ 0.0099), being greater in women, and in peroneal nerve latency $(\mathrm{H}: 3.6 \pm 1.4 ; \mathrm{M}: 3.3 \pm 1.4 ; \mathrm{p}=$ 0.0091 ) being greater in men.

To define the reference value of the variables that followed a normal distribution, we took the values below the upper limit of the range established with the standard deviation (2 $\mathrm{SD})$ for latency, and the values above the lower limit of the range established with the standard deviation (2 SD) for amplitude and velocity (Table 4). Likewise, the percentiles of the amplitude parameters of sensory nerve conductions were analyzed, which did not follow a normal distribution (Table 4).
Table 4

Reference values

\begin{tabular}{|c|c|c|c|}
\hline \multicolumn{4}{|c|}{ Motor nerve conduction } \\
\hline Median & $\begin{array}{l}\mathrm{n}=154 \\
\text { Total }\end{array}$ & $\begin{array}{c}\mathrm{n}=62 \\
\text { Men }\end{array}$ & $\begin{array}{r}\mathrm{n}=92 \\
\text { Women }\end{array}$ \\
\hline \multirow{3}{*}{$\begin{array}{l}\text { Latency } \\
\text { Amplitude } \\
\text { Velocity }\end{array}$} & $\leq 4.2$ & $\leq 4.1$ & $\leq 4.2$ \\
\hline & $\geq 3.1$ & $\geq 3$ & $\geq 3$ \\
\hline & $\geq 50.8$ & $\geq 50.4$ & $\geq 50.7$ \\
\hline Ulnar & Total & Men & Women \\
\hline Latency & $\leq 3.6$ & $\leq 3.6$ & $\leq 3.5$ \\
\hline Amplitude & $\geq 4.6$ & $\geq 4.8$ & $\geq 4.6$ \\
\hline Velocity & $\geq 49$ & $\geq 51.2$ & $\geq 47.6$ \\
\hline Tibial & Total & Men & Women \\
\hline Latency & $\leq 4.4$ & $\leq 4.7$ & $\leq 4.1$ \\
\hline Amplitude & $\geq 5$ & $\geq 5.8$ & $\geq 5$ \\
\hline Velocity & $\geq 41.4$ & $\geq 40.6$ & $\geq 41.8$ \\
\hline Peroneal & Total & Men & Women \\
\hline Latency & $\leq 4.8$ & $\leq 5$ & $\leq 4.7$ \\
\hline Amplitude & $\geq 1.56$ & $\geq 1.5$ & $\geq 1.7$ \\
\hline Velocity & $\geq 42$ & $\geq 42.4$ & $\geq 42.4$ \\
\hline \multicolumn{4}{|c|}{ Sensory nerve conduction } \\
\hline & $\mathrm{n}=154$ & $\mathrm{n}=62$ & $\mathrm{n}=92$ \\
\hline Median & Total & Men & Women \\
\hline Latency & $\leq 2.82$ & $\leq 2.78$ & $\leq 2.84$ \\
\hline Amplitude & $\geq 24^{*}$ & $\geq 26$ & $\geq 21$ \\
\hline Velocity & $\geq 45$ & $\geq 45$ & $\geq 45$ \\
\hline Ulnar & Total & Men & Women \\
\hline Latency & $\leq 2.7$ & $\leq 2.76$ & $\leq 2.74$ \\
\hline Amplitude & $\geq 16^{*}$ & $\geq 16$ & $\geq 17$ \\
\hline Velocity & $\geq 46$ & $\geq 45.3$ & $\geq 46.2$ \\
\hline Sural & Total & Men & Women \\
\hline Latency & $\leq 2.22$ & $\leq 2.34$ & $\leq 2.22$ \\
\hline Amplitude & $\geq 7^{*}$ & $\geq 7$ & $\geq 6.7$ \\
\hline Velocity & $\geq 41.2$ & $\geq 40$ & $\geq 42$ \\
\hline \multicolumn{4}{|c|}{ Late responses } \\
\hline & $\mathrm{n}=142$ & $\mathrm{n}=60$ & $\mathrm{n}=82$ \\
\hline$F$-wave & Total & Men & Women \\
\hline Latency & $\leq 51$ & $\leq 51.6$ & $\leq 49.5$ \\
\hline$H$-reflex & Total & Men & Women \\
\hline Latency & $\leq 33$ & $\leq 33.5$ & $\leq 32.9$ \\
\hline
\end{tabular}

*This value corresponds to the 15 th percentile since variables do not follow normal distribution

\section{Discussion}

In this study, motor and sensory nerve conductions and late responses were performed in asymptomatic people between 18 and 65 years old, to characterize a young representative sample of the population of Hospital Universitario San Ignacio, in order to establish normality values for the Electrodiagnostic Laboratory.

Latency, amplitude and velocity were analyzed for motor nerve conduction of the median, ulnar, tibial and peroneal nerves, and for sensory nerve conduction of the median, ulnar and sural nerves, and latency of the late responses (F-wave and $\mathrm{H}$-reflex). Normality values were determined according to the parameter to be analyzed. For latency, values below the upper limit of the range are defined as normal, since finding it prolonged would imply myelin damage. For amplitude and velocity, values above the 
lower limit of the range are defined as normal, because finding it diminished would imply axonal or myelin damage, respectively. Normality values were obtained as established for our laboratory population, shown in Table 4.

The reference values obtained are similar to those of international studies found in the literature $(2-4,6,7,9,11,12)$. However, some differences were found, mainly in latencies of median, tibial, peroneal, sensory ulnar and sural nerve, and in amplitudes of median, ulnar and peroneal nerve, which may be due to characteristics of our population, such as difference in height. Hence the importance of obtaining reference parameters for our laboratory.

The group analysis determined a statistically significant difference in tibial nerve amplitude and peroneal nerve latency, which could be directly influenced by the difference in height among the groups, with the total mean being 167 $\mathrm{cm}$, greater in men than in women $(173 \mathrm{~cm}$ and $163 \mathrm{~cm}$, respectively).

The results obtained for the reference values can be applied to the patient population studied at the Electrodiagnostic Laboratory of Hospital Universitario San Ignacio. One of the limitations in comparing our results with those of different international studies is the difference in the recording techniques, given the great diversity of methods used, the difference in ages of the subjects analyzed, the different sample sizes, the techniques of data analysis and the generation of normality ranges.

\section{Conclusion}

We established reference parameters for motor and sensory nerve conductions of the median, ulnar, tibial and peroneal motor nerves and the median, ulnar and sural sensory nerves, and late responses (F-wave and H-reflex) for the Electrodiagnostic Laboratory of Hospital Universitario San Ignacio. Most of these parameters correlate with the current reference data, with some differences that could be related to the height, sex and characteristics of our population. However, further studies are required to establish these differences.

\section{Conflict of interest}

The authors declare no conflict of interest.

\section{Acknowledgments}

To Camilo García-Pardo, from the Faculty of Economics of the Pontificia Universidad Javeriana.

\section{References}

1. Aminoff M. Electrodiagnosis in clinical neurology. New York: Elsevier; 2005.

2. Buschbacher R. Median 14$\mathrm{cm}$ and 7- $\mathrm{cm}$ antidromic sensory studies to digits two and three. Am J Phys Med Rehabil. 1999;78(6):S53-62. https://doi.org/10. 1097/00002060-199911001-00011

3. Buschbacher R. Median nerve motor conduction to the abductor pollicis brevis. Am J Phys Med Rehabil. 1999;78(6):S1-8. https://doi.org/10.10 97/00002060-199911001-00002

4. Buschbacher R. Peroneal nerve motor conduction to the extensor digitorum brevis. Am J Phys Med Rehabil. 1999;78(6):S26-31. https://doi.org/10. 1097/00002060-199911001-00006

5. Buschbacher R. Tibial nerve motor conduction to the abductor hallucis. Am J Phys Med Rehabil. 1999;78(6):S15-20. https://doi.org/10. 1097/00002060-199911001-00004

6. Buschbacher R. Ulnar $14-\mathrm{cm}$ and $7-\mathrm{cm}$ antidromic sensory studies to the fifth digit: reference values derived from a large population of normal subjects. Am 
J Phys Med Rehabil. 1999;78(6 Suppl):S63-8. https://doi.org/10.1097/ 00002060-199911001-00012

7. Buschbacher R. Ulnar nerve motor conduction to the abductor digiti minimi. Am J Phys Med Rehabil. 1999;78(6):S9-14. https://doi.org/10.1 097/00002060-199911001-00003

8. Buschbacher R. Sural and saphenous 14- $\mathrm{cm}$ antidromic sensory nerve conduction studies. Am J Phys Med Rehabil. 1999;78(6):421-6.

9. Álvarez O, Jiménez A, Gómez

J, Gómez N, Pira J. Medición y descripción de los valores de neuroconducciones y electromiografía de un grupo poblacional adjunto al Hospital Militar Central de Bogotá, definiendo rangos de normalidad [internet]. Bogotá: Universidad Militar Nueva Granada; 2013. Disponible en: http://hdl.handle.net/10654/12415

10. Barrera Castro SM, Ortiz Corredor F. Valores de referencia de los estudios de neuroconducción de miembros inferiores en adultos jóvenes. Rev Salud Pública. 2014;16(3):443-52. http s://doi.org/10.15446/rsap.v16n3.35592

11. Cobos E, Burgos J. Potenciales evocados multimodales en población mexicana sana de 17 a 64 años. México: Universidad Nacional Autónoma de México; 2014.

12. Hidalgo B, Larios D, Ortiz K, Aguilar R, Rápalo S, Maradiaga E, et al. Parameters of nerve conduction motor and sensory in healthy adults. Rev Médica los Postgrados de Medicina (Honduras). 2009;12(1):31-8.
ID card number:

Age:

Height (in $\mathrm{cm}$ ):

Contact:

Inclusion criteria (check Yes or No):

Age between 18 and 65 years:

You are Colombian:

Exclusion criteria (check Yes or No):

\section{Exclusion criteria (check Yes or No):}

Tingling symptoms:

Lack of feeling:

Burning or electric pain in extremities:

\begin{tabular}{lll}
\hline Known & peripheral & neuropathy: \\
Hereditary & (familial) neuropathy:
\end{tabular}

Compressive neuropathy (e.g., carpal tunnel syndrome):

Autoimmune diseases:

Spinal diseases or radiculopathies:

Metabolic diseases:

History of cancer/chemo use:

Neuromuscular diseases (e.g., myasthenia gravis):

Amputation of a limb:

Contraindication for supine position:

\section{Supplementary material}

General information:

Female Male 